\title{
The associations of eating behavior and dietary intake with metabolic syndrome in Japanese: Saku cohort baseline study
}

\author{
Akemi Morita ${ }^{1 *}$, Naomi Aiba², Motohiko Miyachi ${ }^{3}$, Shaw Watanabe ${ }^{4}$ and for the Saku Cohort Study Group
}

\begin{abstract}
Background: The prevention of metabolic syndrome (MetS) is a major public health concern in Japan. The effects of the relationship between eating behavior and nutritional intake on MetS remained unclear.

To evaluate nutrition's role in preventing or exacerbating MetS, we examined the associations among eating behavior, nutritional intake, and MetS for the baseline study in the cohort subjects undergone health checkups.

Methods: Four thousand and four hundred forty-seven Japanese men and women were enrolled at the Saku Central Hospital. They received an anthropometric and clinical examination and were assessed for present illness, lifestyle factors such as physical activity, smoking, drinking, and dietary habits at the enrollment. Eating behavior was analyzed by the Sakata's Eating Behavior Questionnaire. Dietary assessment was made using a brief selfadministered diet history questionnaire. Two thousand and six hundred two men and 1844 women aged more than 20 were analyzed.
\end{abstract}

Results: The mean age in men and women were 59.2 and 58.4 years old and the mean body mass index (BMI) were 23.7 and $22.3 \mathrm{~kg} / \mathrm{m}^{2}$, respectively. The percentages of MetS were 20.6 in men and 6.1 in women. In some nutrients, significantly higher energy-adjusted intakes in subjects without MetS than with Mets appeared both in men and women after age adjustment. After adjusting by age, energy-adjusted intake beverages in men and cereals in women were significantly higher in subjects with MetS than those without MetS. The scores of all the categories in eating behavior were significantly worse in subjects with MetS than those without MetS.

Conclusions: The differences in dietary intake between subjects with Mets and without Mets were relatively small. The scores of all the categories in eating behavior were worse in subjects with MetS than without MetS. It was suggested that the problem lay in the quality of diet, not in the quantity, caused by bad eating habits. The potential influence of eating behavior and nutritional intake on MetS was presented in men and women.

Keywords: Metabolic syndrome (MetS), Dietary intake, Eating behavior, Baseline study

\footnotetext{
* Correspondence: akemimo@doc.medic.mie-u.ac.jp

${ }^{1}$ Department of Public Health and Occupational Medicine, Mie University Graduate School of Medicine, 2-174 Edobashi, Tsu, Mie 5148507, Japan

Full list of author information is available at the end of the article
}

(c) The Author(s). 2020 Open Access This article is licensed under a Creative Commons Attribution 4.0 International License, which permits use, sharing, adaptation, distribution and reproduction in any medium or format, as long as you give appropriate credit to the original author(s) and the source, provide a link to the Creative Commons licence, and indicate if changes were made. The images or other third party material in this article are included in the article's Creative Commons licence, unless indicated otherwise in a credit line to the material. If material is not included in the article's Creative Commons licence and your intended use is not permitted by statutory regulation or exceeds the permitted use, you will need to obtain permission directly from the copyright holder. To view a copy of this licence, visit http://creativecommons.org/licenses/by/4.0/. The Creative Commons Public Domain Dedication waiver (http://creativecommons.org/publicdomain/zero/1.0/) applies to the data made available in this article, unless otherwise stated in a credit line to the data. 


\section{Background}

Metabolic syndrome (MetS) is a cluster of cardiovascular risk factors, including abdominal obesity, hypertension, dyslipidemia, and glucose intolerance $[1,2]$. The importance of MetS lies in its associated risk of cardiovascular disease and type 2 diabetes. The prevention of MetS and type 2 diabetes is a major challenge in Health Japan 21 [3]. The available scientific evidence on the associations between lifestyle modifications and MetS and its components is reviewed to derive recommendations for MetS prevention and management [4]. Especially, dietary habits change are the main therapeutic strategy for the treatment and management of obesity and MetS, but the most effective dietary pattern for its management has not been unclear [5].

The diet consumed by the Japanese, so-called Washoku, is widely perceived to be healthy owing to the low prevalence of coronary artery disease and relatively good life expectancy of the Japanese [6, 7]. However, studies have consistently determined that compliance with the Japanese healthy eating guidelines (Japanese Food Guide Spinning Top) is simultaneously associated with both favorable aspects of dietary intake such as higher intake of dietary fiber and micronutrients, and unfavorable aspects such as higher intake of saturated fats and sodium $[8,9]$. Moreover, these large prospective cohort studies showed an inverse association between compliance with these guidelines and the major causes of mortality. A recent systematic review of Japanese studies that obtained dietary patterns presented that the food groups which contribute to dietary patterns termed healthy (vegetables, including potatoes, mushrooms, and seaweeds; fruits; soy products) are reasonably consistent with those often observed in Western countries [10].

To prevent MetS and subsequent diseases such as type 2 diabetes, it is required to elucidate the Japanese healthy diet's component and pattern and its effect on MetS.

A series of epidemiological and clinical studies was carried out in Saku, Nagano Prefecture in Japan. Since 1990, a population-based Japan Public Health Center cohort study, consisting of 40-59-year-old residents, has been conducted in Saku [11]. According to the prevention of MetS, we established a clinical study (Saku Control Obesity Program (SCOP)) and compared the efficacy of SCOP intervention (i.e., change in the rate of metabolic syndrome before and after the intervention) [12-15]. In Saku Health Dock Center each year, about 7000 examinees have come to the center for a health checkup, including an oral glucose tolerance test (OGTT) by $75 \mathrm{~g}$ glucose intake, endoscopy, and recently abdominal CT, in addition to the routine laboratory test and physical checkups. The Saku Health Dock Center database contains approximately 196,000 records connecting to the hospital database. Our intervention and cohort study represented an approach incorporating extensive biological markers as health screening data, blood, urine, and gene storage for future analyses. We selected this area because of a long collaborative history for the primary prevention of chronic diseases.

To evaluate nutrition's role in preventing or exacerbating MetS, we examined the associations among eating behavior, nutritional intake, and MetS for the baseline study in the cohort subjects undergone health checkups in the Saku Health Dock Center.

\section{Methods \\ Study design}

We performed a cross-sectional study using the baseline data of the Saku Cohort Study for Healthy Aging launched in 2009 at Saku Central Hospital, which is one of the core hospitals in Nagano Prefecture, Japan. The Saku Cohort Study has been described elsewhere [16]. In brief, this cohort study was designed to determine the risk factors for chronic diseases, including type 2 diabetes, cardiovascular disease, and cancer, among the community residents in Nagano Prefecture.

\section{Study population}

Participants who visited Saku Central Hospital for a health checkup between May 2009 and March 2013, and who agreed to participate in the cohort, were included in the study. From the study population at baseline $(n=$ 4447 ), we excluded one subject aged $<20$ years old. The remaining 4446 participants $(2602$ men and 1844 women) were included for analysis.

\section{Measures}

The general health screening included demographic characteristics (e.g., age and gender), medical histories, and physical and clinical examination. Besides, we assessed the participants' physical activity levels, and all participants completed self-administered questionnaires regarding diet and mental health.

\section{Physical and clinical examination}

Each participant underwent all the examinations on the same morning after an overnight fast $(12 \mathrm{~h})$. The height (cm) and weight $(\mathrm{kg})$ of the subject were measured with an automatic scale (Tanita, BF-220, Tokyo, Japan), in light clothing. The body mass index (BMI) was calculated as the weight $(\mathrm{kg})$ divided by the squared height $\left(\mathrm{m}^{2}\right)$. Waist circumference was measured twice at the umbilicus level while the subject was in a standing position using a fiberglass measuring tape; the average measurement was used for the analysis. Blood pressure was measured while the subject was in a sitting position using a validated automated blood pressure monitor (ES-H55; Terumo, Tokyo, Japan). Blood pressure was 
measured twice to calculate the average of the two values for the analysis.

About half of the participants were assessed the crosssectional area of visceral fat tissue (visceral fat area: VFA) based on a computed tomography (CT) scan at the level of the umbilicus while the subject was in a supine position (Fat scan; N2 system Corp., Japan).

Blood samples were collected for the measurement of fasting plasma glucose, insulin, hemoglobin A1c (HbA1c), serum total cholesterol, high-density lipoprotein (HDL) cholesterol, low-density lipoprotein (LDL) cholesterol; and triglyceride, $\gamma$-glutamyl transferase, uric acid, blood urea nitrogen, and creatinine levels.

The values for HbA1c were collected as Japan Diabetes Society (JDS) values, and then converted to National Glycohemoglobin Standardization Program (NGSP) values using the following conversion formula: HbA1c (NGSP) = $1.02 \times$ HbA1c $($ JDS $)+0.25 \%$. The homeostasis model assessment of insulin resistance (HOMA-IR) was calculated as follows: fasting insulin $(\mu \mathrm{IU} / \mathrm{ml}) \times$ fasting glucose $(\mathrm{mg} /$ dL)/405.

\section{Dietary intake and dietary habits}

The previous month's dietary intake was assessed using a validated brief self-administered diet history questionnaire (BDHQ) [17]. The BDHQ is a structured questionnaire that inquiries about 58 food and beverage items; the specified serving sizes are described in terms of the natural portions or the standard weight and volume measurements of the servings commonly consumed in the general Japanese population. The intake of energy and nutrients, and food was calculated using an ad hoc computer program for BDHQ. The BDHQ is a short form of the comprehensive version of a validated selfadministered diet history questionnaire (DHQ). The validation of the DHQ and BDHQ was performed using weighed dietary records or biological markers. The validity of the energy-adjusted intakes of many nutrients and food groups has been previously studied in the adult Japanese population [18].

Participants' eating behavior was analyzed by a questionnaire established by Sakata in the Manual of Obesity 2006 written by the Japan Society for the Study of Obesity [19]. The questionnaire's 55 statements are based on the statements given by obese people in a clinical survey, and subjects were asked to agree or disagree on a 4point Likert scale: (1) disagree, (2) sometimes, (3) having a trend, and (4) agree. The questionnaire is assessed by categorizing 54 items into the following eight categories: (1) perception gap about constitution and weight, (2) motivation for eating, (3) substitute eating, (4) perception gap about feeling of fullness and hunger, (5) bad eating habits, (6) contents of diet, (7) eating pattern, and (8) total of all of them. Each category score was calculated by sex. One is a dummy question. The higher score in this questionnaire indicated worse in eating behavior (see Appendix 1).

\section{Metabolic syndrome}

Metabolic syndrome was diagnosed consistent with the criteria of the Examination Committee for the Criteria for the Diagnosis of Metabolic Syndrome in Japan 2005 [20] The definition of metabolic syndrome was abdominal obesity with a waist circumference $\geq 85 \mathrm{~cm}$ for men and $\geq 90 \mathrm{~cm}$ for women and two or more of the following three risk factors: (1) high blood pressure (systolic blood pressure $\geq 130 \mathrm{mmHg}$ and/or diastolic blood pressure $\geq 85 \mathrm{mmHg}$, or treatment for previously diagnosed hypertension), (2) hyperglycemia (fasting glucose $\geq 110$ $\mathrm{mg} / \mathrm{dL}$ or treatment for previously diagnosed type 2 diabetes), and (3) dyslipidemia (triglyceride levels $\geq 150$ $\mathrm{mg} / \mathrm{dL}$ and/or HDL-cholesterol $<40 \mathrm{mg} / \mathrm{dL}$, or treatment for previously diagnosed dyslipidemia).

\section{Statistical analysis}

Baseline characteristics were compared between sexes and between subjects with MetS and without MetS using the unpaired $t$ test for continuous variables. Crude value and energy-adjusted value, which were calculated as the amount of food consumed divided by $1000 \mathrm{kcal}$ (density model), of dietary intake were analyzed. Comparisons of dietary intake adjusted for confounding factors were performed by analysis of covariance (ANCOVA) when necessary. Pearson or Spearman correlation coefficients $(r)$ were calculated to evaluate associations among physical and clinical findings, dietary intakes, and eating behavior. $P<0.05$ was considered significant. Statistical analyses were performed using SPSS statistical software (Version 25.0 J; IBM Japan Inc., Tokyo).

\section{Results}

In total, 4447 Japanese men and women participated in our cohort. In this study, 2602 men and 1844 women aged 20 and over were analyzed.

Table 1 shows the basic characteristics of the subjects. The mean age in men and women were 59.2 and 58.4 years old and the mean BMI were 23.7 and $22.3 \mathrm{~kg} / \mathrm{m}^{2}$, respectively. The average waist circumference in men was $85.3 \mathrm{~cm}$ which met MetS criteria in Japan. Visceral fat areas were measured by CT in 1293 men and 841 women. Visceral obesity was $58.0 \%$ in men and $20.3 \%$ in women diagnosed according to the high visceral fat area $\left(\geq 100 \mathrm{~cm}^{2}\right)$.

Table 2 shows daily nutritional intake in men and women. Macronutrients and major micronutrients which were possible to affect metabolic risk were presented in Table 2 [5-10]. Energy and crude nutrient intakes excepting potassium, calcium, and vitamin D were 
Table 1 Basic characteristics of the subjects

\begin{tabular}{lll}
\hline & $\begin{array}{l}\text { Men } \\
(\boldsymbol{n}=\mathbf{2 6 0 2})\end{array}$ & $\begin{array}{l}\text { Women } \\
(\boldsymbol{n}=\mathbf{1 8 4 4})\end{array}$ \\
\hline Age (years) & $59.2 \pm 10.0$ & $58.4 \pm 9.8$ \\
Height (cm) & $168.1 \pm 6.1$ & $155.6 \pm 5.6$ \\
Weight (kg) & $67.1 \pm 9.7$ & $54.1 \pm 8.2$ \\
BMI (kg/m $\left.{ }^{2}\right)$ & $23.7 \pm 2.9$ & $22.3 \pm 3.2$ \\
Waist circumference (cm) & $85.3 \pm 8.0$ & $80.7 \pm 9.0$ \\
Visceral fat area (cm $\left.{ }^{2}\right)$ & $114.1 \pm 44.7$ & $73.0 \pm 36.7$ \\
Systolic blood pressure (mmHg) & $119.9 \pm 15.0$ & $112.4 \pm 15.3$ \\
Diastolic blood pressure (mmHg) & $75.6 \pm 11.1$ & $69.4 \pm 11.2$ \\
HDL cholesterol (mg/dL) & $54.8 \pm 13.5$ & $64.4 \pm 14.3$ \\
LDL cholesterol (mg/dL) & $118.6 \pm 28.8$ & $122.7 \pm 29.0$ \\
Triglycerides (mg/dL) & $125.0 \pm 77.3$ & $92.5 \pm 49.7$ \\
Y-glutamyl transferase (IU/L) & $47.9 \pm 51.8$ & $23.3 \pm 22.0$ \\
Uric acid (mg/dL) & $6.1 \pm 1.2$ & $4.7 \pm 1.0$ \\
Blood urea nitrogen (mg/dL) & $14.7 \pm 3.6$ & $13.8 \pm 3.3$ \\
Creatinine (mg/dL) & $0.86 \pm 0.18$ & $0.64 \pm 0.11$ \\
Fasting plasma glucose (mg/dL) & $104.7 \pm 17.5$ & $99.0 \pm 14.6$ \\
HbA1c (\%) & $5.7 \pm 0.6$ & $5.7 \pm 0.5$ \\
Fasting insulin ( $\mu \mathrm{U} / \mathrm{mL})$ & $5.1 \pm 3.6$ & $4.6 \pm 2.8$ \\
HOMA-IR & $\underline{1.4} \pm \underline{1.2}$ & $\underline{1.2} \pm \underline{0.9}$ \\
\hline \hline Values are mans $5 \mathrm{SD}$ &
\end{tabular}

Values are means $\pm S D$

significantly higher in men than in women. However, all energy-adjusted nutrients intakes were significantly higher in women than in men.

The following analyses were conducted by sex.

The percentage of MetS was higher in men (20.6\%) than in women (6.1\%). Figure 1 shows the prevalence of diseases according to "Metabolic Syndrome Criteria", as high blood pressure, high glucose, and dyslipidemia. The numbers of high blood pressure, high glucose, and dyslipidemia were 842 (men 690, women 152), 472 (men 393, women 79), and 717 (men 599, women 118), respectively. The subjects with MetS were older and had worse anthropometric and clinical characteristics than those without MetS in both men and women (Table 3).

The association between dietary intake and MetS was presented in Tables 4 and 5 . We compared nutritional intake between subjects with MetS and without MetS. Aside from sodium and vitamin D intake, both crude and energy-adjusted nutrients intakes were higher in subjects without MetS than with Mets in men. There were significant differences in some crude and energyadjusted nutrient intake between men with MetS and without MetS. In women, there was no significant difference in all crude nutrients intakes between subjects with MetS and without MetS. However, women with MetS had significantly higher energy-adjusted sodium intake than those without MetS. After adjusting by age as a confounding factor, the association between sodium intake and MetS was not found both in men and women. In some nutrients, significantly higher energy-adjusted intakes in subjects without MetS than with Mets appeared both in men and women after age adjustment (data not shown).

In Table 5, the food group's crude food intakes tended to be higher in subjects without MetS than with MetS, except beverages in men, cereals in women, and fishes in both sexes. In some crude food intakes, including beverages, there were significant differences between subjects with MetS and without MetS. Energy-adjusted food intake showed a similar trend in men. However, in women, energy-adjusted cereal and some other food intakes were slightly higher in subjects with MetS than without MetS. After adjusting by age, energy-adjusted intake beverages in men and cereals in women were significantly higher in subjects with MetS than without MetS. Energy-adjusted intake of some foods in men and potatoes in women showed significantly higher without MetS than with Mets after age adjustment (data not shown).

Besides, we analyzed the associations between eating behavior and MetS according to eight categories of the questionnaire. The scores of all the eating behavior categories were significantly worse in subjects with MetS than those without MetS (Fig. 2).

In correlation analysis among basic characteristics, dietary intake, and eating behavior, nearly all the correlation coefficients were less than 0.3. Exceptionally, positive correlations were found between age and energyadjusted calcium (in both sexes), protein, sodium, potassium, and vitamin $B_{2}$ in women. In contrast, negative correlations were found between the eating behavior scale of contents of meals and energy-adjusted potassium and calcium in women (data not shown).

\section{Discussions}

The present study's main results were (1) dietary intakes in the subjects with Mets were not higher than in those without Mets, except some nutrients and foods, and (2) eating behaviors were significantly worse in subjects with MetS than without MetS.

MetS is one of the most important problems of Japanese health policy. The prevalences of strongly suspected MetS were $24.7 \%$ in men and $9.4 \%$ in women in the 2012 National Health and Nutrition Survey (NHNS), Japan [21]. A higher prevalence of metabolic syndrome was reported recently (30.4\% in men and $11.9 \%$ in women, 2018 NHNS). Our study presented a lower prevalence of MetS in our subjects. The difference in prevalence between our study and NHNS was attributable that the prevalence from NHNS was estimated from limited biomarkers and medical history. In the diseases, 
Table 2 Daily nutritional intake of the subjects

\begin{tabular}{|c|c|c|c|c|c|c|}
\hline & & Crude & & & Energy-adjusted & \\
\hline & & Men $(n=2602)$ & Women $(n=1844)$ & & Men $(n=2602)$ & Women $(n=1844)$ \\
\hline Energy & (kcal) & $2380 \pm 683$ & $1933 \pm 515^{*}$ & & & \\
\hline Protein & (g) & $89.7 \pm 33.6$ & $80.5 \pm 28.0^{*}$ & (g/1000 kcal) & $37.5 \pm 7.3$ & $41.4 \pm 7.5^{*}$ \\
\hline Animal protein & (g) & $52.4 \pm 26.1$ & $48.0 \pm 22.1^{*}$ & (g/1000 kcal) & $21.7 \pm 7.4$ & $24.5 \pm 7.9^{*}$ \\
\hline Plant protein & (g) & $37.2 \pm 11.4$ & $32.5 \pm 9.2^{*}$ & (g/1000 kcal) & $15.7 \pm 2.6$ & $16.9 \pm 2.4^{*}$ \\
\hline Fat & (g) & $63.8 \pm 24.2$ & $58.9 \pm 20.7^{*}$ & (g/1000 kcal) & $26.7 \pm 6.0$ & $30.2 \pm 5.6^{*}$ \\
\hline Animal fat & (g) & $29.6 \pm 13.8$ & $27.2 \pm 11.4^{*}$ & (g/1000 kcal) & $12.3 \pm 4.0$ & $13.9 \pm 3.9^{*}$ \\
\hline Plant fat & (g) & $34.1 \pm 13.7$ & $31.8 \pm 12.6^{*}$ & (g/1000 kcal) & $14.3 \pm 4.1$ & $16.3 \pm 4.4^{*}$ \\
\hline Saturated fatty acid & (g) & $15.9 \pm 6.5$ & $15.1 \pm 5.6^{*}$ & (g/1000 kcal) & $6.6 \pm 1.8$ & $7.7 \pm 1.7^{*}$ \\
\hline n-3 polyunsaturated fatty acid & (g) & $3.7 \pm 1.7$ & $3.4 \pm 1.5^{*}$ & (g/1000 kcal) & $1.5 \pm 0.5$ & $1.7 \pm 0.5^{*}$ \\
\hline n-6 polyunsaturated fatty acid & (g) & $13.0 \pm 4.9$ & $11.6 \pm 4.4^{*}$ & (g/1000 kcal) & $5.5 \pm 1.4$ & $6.0 \pm 1.5^{*}$ \\
\hline Carbohydrate & (g) & $313 \pm 96$ & $259 \pm 70^{*}$ & (g/1000 kcal) & $132 \pm 20$ & $135 \pm 17^{*}$ \\
\hline Soluble dietary fiber & (g) & $4.0 \pm 1.8$ & $4.1 \pm 1.6^{*}$ & (g/1000 kcal) & $1.7 \pm 0.6$ & $2.1 \pm 0.6^{*}$ \\
\hline Insoluble dietary fiber & (g) & $11.5 \pm 4.5$ & $11.5 \pm 4.3^{*}$ & (g/1000 kcal) & $4.9 \pm 1.4$ & $6.0 \pm 1.6^{*}$ \\
\hline Total dietary fiber & (g) & $16.1 \pm 6.5$ & $16.1 \pm 6.1^{*}$ & (g/1000 kcal) & $6.8 \pm 2.1$ & $8.3 \pm 2.3^{*}$ \\
\hline Sodium & (mg) & $5516 \pm 1689$ & $4790 \pm 1438^{*}$ & (mg/1000 kcal) & $2358 \pm 493$ & $2505 \pm 500^{*}$ \\
\hline Salt equivalent & (g) & $13.9 \pm 4.3$ & $12.1 \pm 3.6^{*}$ & (g/1000 kcal) & $5.9 \pm 1.2$ & $6.3 \pm 1.3^{*}$ \\
\hline Potassium & (mg) & $3380 \pm 1287$ & $3317 \pm 1184$ & (mg/1000 kcal) & $1423 \pm 372$ & $1713 \pm 410^{*}$ \\
\hline Calcium & (mg) & $701 \pm 298$ & $687 \pm 275$ & (mg/1000 kcal) & $296 \pm 95$ & $354 \pm 102^{*}$ \\
\hline Magnesium & (mg) & $337 \pm 117$ & $310 \pm 103^{*}$ & (mg/1000 kcal) & $142 \pm 29$ & $160 \pm 32^{*}$ \\
\hline Vitamin D & $(\mu \mathrm{g})$ & $21.6 \pm 15.1$ & $21.0 \pm 14.0$ & ( $\mu \mathrm{g} / 1000$ kcal) & $8.9 \pm 5.0$ & $10.6 \pm 5.8^{*}$ \\
\hline Vitamin B1 & (mg) & $0.97 \pm 0.36$ & $0.93 \pm 0.31^{*}$ & (mg/1000 kcal) & $0.40 \pm 0.09$ & $0.48 \pm 0.09^{*}$ \\
\hline Vitamin B2 & (mg) & $1.68 \pm 0.61$ & $1.55 \pm 0.51^{*}$ & (mg/1000 kcal) & $0.71 \pm 0.18$ & $0.80 \pm 0.17^{*}$ \\
\hline
\end{tabular}

Values are crude and energy-adjusted means \pm SD

*Significant difference between sexes $(p<0.05)$

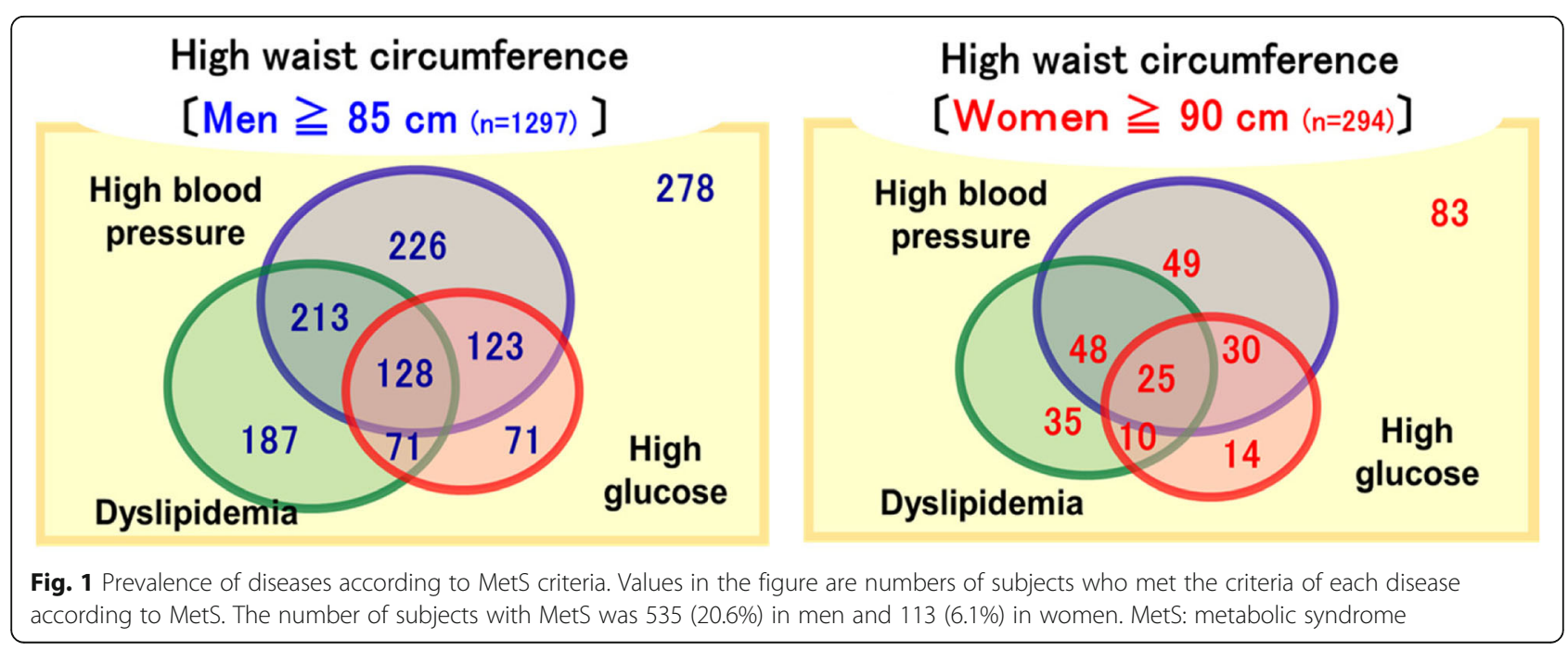


Table 3 Associations between basic characteristics and MetS

\begin{tabular}{|c|c|c|c|c|}
\hline & Men & & Women & \\
\hline & MetS $(n=535)$ & w/o MetS $(n=2067)$ & MetS $(n=113)$ & w/o MetS $(n=1731)$ \\
\hline Age (years) & $61.1 \pm 8.9$ & $58.6 \pm 10.2^{*}$ & $63.1 \pm 8.4$ & $58.1 \pm 9.8^{*}$ \\
\hline Height (cm) & $168.4 \pm 5.8$ & $168.0 \pm 6.2$ & $154.4 \pm 5.4$ & $155.7 \pm 5.6^{*}$ \\
\hline Weight (kg) & $74.2 \pm 9.1$ & $65.2 \pm 9.0^{*}$ & $66.0 \pm 7.7$ & $53.3 \pm 7.7^{*}$ \\
\hline $\mathrm{BMI}\left(\mathrm{kg} / \mathrm{m}^{2}\right)$ & $26.1 \pm 2.7$ & $23.1 \pm 2.6^{*}$ & $27.7 \pm 2.9$ & $22.0 \pm 2.9^{*}$ \\
\hline Waist circumference (cm) & $92.6 \pm 6.3$ & $83.4 \pm 7.3^{*}$ & $96.7 \pm 5.7$ & $79.7 \pm 8.3^{*}$ \\
\hline Visceral fat area $\left(\mathrm{cm}^{2}\right)$ & $142.6 \pm 46.0$ & $104.4 \pm 39.8^{*}$ & $115.6 \pm 37.7$ & $67.8 \pm 33.1^{*}$ \\
\hline Systolic blood pressure $(\mathrm{mmHg})$ & $127.4 \pm 14.9$ & $117.6 \pm 14.4^{*}$ & $127.8 \pm 16.4$ & $111.4 \pm 14.7^{*}$ \\
\hline Diastolic blood pressure $(\mathrm{mmHg})$ & $80.4 \pm 10.9$ & $74.0 \pm 10.8^{*}$ & $78.4 \pm 11.6$ & $68.9 \pm 10.9^{*}$ \\
\hline HDL cholesterol (mg/dL) & $49.2 \pm 11.6$ & $56.2 \pm 13.6^{*}$ & $56.6 \pm 12.1$ & $64.9 \pm 14.3^{*}$ \\
\hline LDL cholesterol (mg/dL) & $118.0 \pm 28.6$ & $118.8 \pm 28.9$ & $130.2 \pm 31.4$ & $122.2 \pm 28.8^{*}$ \\
\hline Triglycerides (mg/dL) & $169.3 \pm 97.7$ & $113.5 \pm 66.4^{*}$ & $137.3 \pm 64.2$ & $89.6 \pm 47.2^{*}$ \\
\hline Y-glutamyl transferase (IU/L) & $64.2 \pm 67.1$ & $43.7 \pm 46.1^{*}$ & $37.1 \pm 32.9$ & $22.4 \pm 20.8^{*}$ \\
\hline Uric acid (mg/dL) & $6.4 \pm 1.3$ & $6.1 \pm 1.2^{*}$ & $5.4 \pm 1.2$ & $4.6 \pm 1.0^{*}$ \\
\hline Blood urea nitrogen (mg/dL) & $14.8 \pm 3.8$ & $14.6 \pm 3.6$ & $14.1 \pm 3.6$ & $13.8 \pm 3.3$ \\
\hline Creatinine (mg/dL) & $0.87 \pm 0.17$ & $0.85 \pm 0.19^{*}$ & $0.64 \pm 0.14$ & $0.63 \pm 0.11$ \\
\hline Fasting plasma glucose (mg/dL) & $116.2 \pm 21.8$ & $101.8 \pm 14.8^{*}$ & $116.1 \pm 24.6$ & $97.9 \pm 12.9^{*}$ \\
\hline $\mathrm{HbA1c}(\%)$ & $6.1 \pm 0.7$ & $5.7 \pm 0.5^{*}$ & $6.2 \pm 0.7$ & $5.7 \pm 0.5^{*}$ \\
\hline Fasting insulin $(\mu \mathrm{U} / \mathrm{mL})$ & $7.6 \pm 4.9$ & $4.4 \pm 2.9^{*}$ & $8.7 \pm 4.5$ & $4.4 \pm 2.5^{*}$ \\
\hline HOMA-IR & $2.2 \pm 1.8$ & $1.1 \pm 0.8^{*}$ & $2.6 \pm 1.7$ & $1.1 \pm 0.7^{*}$ \\
\hline
\end{tabular}

Values are means \pm SD. MetS metabolic syndrome, $w / o$ without

*Significant difference between in the subject with MetS and without MetS $(p<0.05)$

according to MetS, the most dominant disease was hypertension in our subjects. However, the prevalence of hypertension or high blood pressure $(\geq 140 \mathrm{mmHg})$ in our subjects was lower than that in NHNS, despite higher sodium intake in our subjects than that in NHNS.

Previous epidemiologic cohort studies have been implemented to explain the correlation between food intake patterns and metabolic risk factors such as hypertension, obesity, and blood lipid profiles [22]. The scientific evidence has consistently shown $[3,4]$ as follows: (1) weight loss through an energy-restricted diet together with increased energy expenditure through physical activity contribute to the prevention and treatment of MetS [23]. (2) A Mediterranean-type diet, which refers to the traditional dietary pattern of countries in the Mediterranean basin, with or without energy restriction, is an effective treatment component [24]. (3) Other dietary patterns (Dietary Approaches to Stop Hypertension (DASH) [25], new Nordic [26], and vegetarian diets [27]) have also been proposed as alternatives for preventing MetS. However, Japanese diet has been not established yet.

Partly as a result of the Japanese population's long life expectancy, dietary habits in Japan have been of interest to researchers from other countries [28]. Recent
Japanese diets typically include high intakes of refined grains (mainly white rice), seaweeds, vegetables, fish, soybean products, and green tea, as well as low intakes of whole grains, processed meat, nuts, and soft drinks [20]. An answer was suggested in a review article. They said that the typical Japanese diet as characterized by plant food and fish, and the modest Westernized diet such as meat, milk, and dairy products might be associated with longevity in Japan [29]. Our subjects in the present study had a higher intake of energy, major nutrients, and foods for almost all food groups than the intake reported in 2012 NHNS, Japan, except for meats in both sexes and beverages in women. Dietary patterns of our participants may well adapt to Japanese healthy diet.

Sakata's eating behavior scale was developed to use for the treatment of obesity in a clinical site. Our result that the subjects with MetS showed worse scores was assumed. The difference between subjects with MetS and without MetS withdrew after adjusting by BMI or weight. In our previous intervention study, we found that the behavior change was more important than food intake [13]. In this cohort, we will assess the subjects' dietary modification during the follow-up period using this scale.

Some limitations of the present study need to be addressed. First, this study was a cross-sectional analysis. 
Table 4 Associations between nutritional intake and MetS

\begin{tabular}{|c|c|c|c|c|c|c|}
\hline \multirow[t]{3}{*}{ Men } & & \multicolumn{3}{|l|}{ Crude } & \multicolumn{2}{|c|}{ Energy adjusted } \\
\hline & & MetS & w/o MetS & & MetS & w/o MetS \\
\hline & & $\underline{(n}=\underline{535)}$ & $\underline{(n=2067)}$ & & $\underline{(n=535)}$ & $\underline{(n}=2067)$ \\
\hline Energy & (kcal) & $2350 \pm 694$ & $2387 \pm 680$ & & & \\
\hline Protein & (g) & $87.3 \pm 32.1$ & $90.3 \pm 34.0$ & (g/1000 kcal) & $37.7 \pm 7.4$ & $37.6 \pm 7.3 \dagger$ \\
\hline Animal protein & (g) & $51.3 \pm 24.6$ & $52.7 \pm 26.5$ & (g/1000 kcal) & $21.6 \pm 7.4$ & $21.8 \pm 7.5$ \\
\hline Plant protein & (g) & $36.0 \pm 11.2$ & $37.5 \pm 11.5^{*}$ & (g/1000 kcal) & $15.5 \pm 2.7$ & $15.8 \pm 2.5^{*} \dagger$ \\
\hline Fat & (g) & $61.4 \pm 23.5$ & $64.4 \pm 24.4^{*}$ & (g/1000 kcal) & $26.0 \pm 6.3$ & $26.8 \pm 5.9^{*}+$ \\
\hline Animal fat & (g) & $28.4 \pm 12.9$ & $30.0 \pm 14.0^{*}$ & (g/1000 kcal) & $11.9 \pm 3.9$ & $12.4 \pm 4.0^{*}+$ \\
\hline Plant fat & (g) & $33.0 \pm 13.6$ & $34.4 \pm 13.7^{*}$ & (g/1000 kcal) & $14.1 \pm 4.3$ & $14.4 \pm 4.0$ \\
\hline Saturated fatty acid & (g) & $15.1 \pm 6.2$ & $16.1 \pm 6.5^{*}$ & (g/1000 kcal) & $6.4 \pm 1.7$ & $6.7 \pm 1.8^{*}+$ \\
\hline n-3 polyunsaturated fatty acid & (g) & $3.7 \pm 1.7$ & $3.7 \pm 1.7$ & (g/1000 kcal) & $1.6 \pm 0.5$ & $1.5 \pm 0.5$ \\
\hline n-6 polyunsaturated fatty acid & (g) & $12.5 \pm 4.8$ & $13.1 \pm 5.0^{*}$ & (g/1000 kcal) & $5.4 \pm 1.5$ & $5.5 \pm 1.4^{*} \dagger$ \\
\hline Carbohydrate & (g) & $302 \pm 98$ & $316 \pm 96^{*}$ & (g/1000 kcal) & $129 \pm 22$ & $133 \pm 19^{*}+$ \\
\hline Soluble dietary fiber & (g) & $3.8 \pm 1.7$ & $4.0 \pm 1.8^{*}$ & (g/1000 kcal) & $1.6 \pm 0.6$ & $1.7 \pm 0.6+$ \\
\hline Insoluble dietary fiber & (g) & $11.1 \pm 4.4$ & $11.6 \pm 4.5^{*}$ & (g/1000 kcal) & $4.8 \pm 1.5$ & $4.9 \pm 1.4 \dagger$ \\
\hline Total dietary fiber & (g) & $15.5 \pm 6.3$ & $16.2 \pm 6.6^{*}$ & (g/1000 kcal) & $6.7 \pm 2.2$ & $6.8 \pm 2.1 \dagger$ \\
\hline Sodium & (mg) & $5525 \pm 1701$ & $5514 \pm 1687$ & (mg/1000 kcal) & $2395 \pm 505$ & $2349 \pm 490$ \\
\hline Salt equivalent & (g) & $13.9 \pm 4.3$ & $13.9 \pm 4.3$ & (g/1000 kcal) & $6.0 \pm 1.3$ & $5.9 \pm 1.2$ \\
\hline Potassium & (mg) & $3274 \pm 1244$ & $3407 \pm 1297^{*}$ & (mg/1000 kcal) & $1398 \pm 376$ & $1430 \pm 371 \dagger$ \\
\hline Calcium & (mg) & $683 \pm 292$ & $706 \pm 299$ & (mg/1000 kcal) & $291 \pm 94$ & $297 \pm 95 \dagger$ \\
\hline Magnesium & (mg) & $330 \pm 114$ & $339 \pm 118$ & (mg/1000 kcal) & $141 \pm 29$ & $142 \pm 29+$ \\
\hline Vitamin D & $(\mu g)$ & $21.9 \pm 15.3$ & $21.6 \pm 15.1$ & $(\mu \mathrm{g} / 1000 \mathrm{kcal})$ & $9.1 \pm 5.0$ & $8.8 \pm 5.0$ \\
\hline Vitamin B1 & (mg) & $0.93 \pm 0.33$ & $0.97 \pm 0.37^{*}$ & (mg/1000 kcal) & $0.39 \pm 0.09$ & $0.41 \pm 0.09^{*}+$ \\
\hline$\underline{\text { Vitamin B2 }}$ & $\underline{(\mathrm{mg})}$ & $\underline{1.64} \pm \underline{0.57}$ & $\underline{1.69} \pm \underline{0.62}$ & $\underline{(\mathrm{mg} / 1000 \mathrm{kcal})}$ & $\underline{0.70} \pm \underline{0.17}$ & $\underline{0.71} \pm \underline{0.18 \dagger}$ \\
\hline \multirow[t]{2}{*}{ Women } & & \multicolumn{3}{|l|}{ Crude } & \multicolumn{2}{|c|}{ Energy adjusted } \\
\hline & & $\begin{array}{l}\text { MetS } \\
\underline{(n=113)}\end{array}$ & $\begin{array}{l}\text { w/o MetS } \\
\underline{(n=1731)}\end{array}$ & & $\begin{array}{l}\text { MetS } \\
\underline{(n=113)}\end{array}$ & $\begin{array}{l}\text { w/o MetS } \\
(\underline{n}=1731)\end{array}$ \\
\hline Energy & (kcal) & $1880 \pm 519$ & $1937 \pm 514$ & & & \\
\hline Protein & (g) & $78.8 \pm 27.5$ & $80.6 \pm 28.0$ & (g/1000 kcal) & $41.9 \pm 8.1$ & $41.3 \pm 7.5$ \\
\hline Animal protein & (g) & $47.3 \pm 21.8$ & $48.0 \pm 22.0$ & (g/1000 kcal) & $25.0 \pm 8.3$ & $24.4 \pm 7.8$ \\
\hline Plant protein & (g) & $31.5 \pm 8.8$ & $32.6 \pm 9.2$ & (g/1000 kcal) & $16.9 \pm 2.4$ & $16.9 \pm 2.4$ \\
\hline Fat & (g) & $56.1 \pm 21.1$ & $59.1 \pm 20.7$ & (g/1000 kcal) & $29.4 \pm 5.8$ & $30.2 \pm 5.5$ \\
\hline Animal fat & (g) & $26.4 \pm 11.5$ & $27.2 \pm 11.4$ & (g/1000 kcal) & $13.9 \pm 4.0$ & $13.9 \pm 3.9$ \\
\hline Plant fat & (g) & $29.7 \pm 12.2$ & $31.9 \pm 12.6$ & (g/1000 kcal) & $15.6 \pm 4.3$ & $16.3 \pm 4.4$ \\
\hline Saturated fatty acid & (g) & $14.4 \pm 5.7$ & $15.1 \pm 5.6$ & (g/1000 kcal) & $7.6 \pm 1.7$ & $7.7 \pm 1.7$ \\
\hline n-3 polyunsaturated fatty acid & (g) & $3.3 \pm 1.5$ & $3.4 \pm 1.5$ & (g/1000 kcal) & $1.7 \pm 0.5$ & $1.7 \pm 0.5$ \\
\hline n-6 polyunsaturated fatty acid & (g) & $11.1 \pm 4.3$ & $11.6 \pm 4.4$ & (g/1000 kcal) & $5.8 \pm 1.5$ & $6.0 \pm 1.5$ \\
\hline Carbohydrate & (g) & $254 \pm 69$ & $260 \pm 70$ & (g/1000 kcal) & $136 \pm 19$ & $135 \pm 17$ \\
\hline Soluble dietary fiber & (g) & $3.8 \pm 1.4$ & $4.1 \pm 1.6$ & (g/1000 kcal) & $2.1 \pm 0.6$ & $2.1 \pm 0.6+$ \\
\hline Insoluble dietary fiber & (g) & $11.2 \pm 4.0$ & $11.5 \pm 4.3$ & (g/1000 kcal) & $6.0 \pm 1.5$ & $6.0 \pm 1.6$ \\
\hline Total dietary fiber & (g) & $15.7 \pm 5.7$ & $16.2 \pm 6.1$ & (g/1000 kcal) & $8.4 \pm 2.2$ & $8.3 \pm 2.3$ \\
\hline Sodium & (mg) & $4817 \pm 1355$ & $4788 \pm 1444$ & (mg/1000 kcal) & $2618 \pm 534$ & $2497 \pm 497^{*}$ \\
\hline Salt equivalent & (g) & $12.2 \pm 3.4$ & $12.1 \pm 3.6$ & (g/1000 kcal) & $6.6 \pm 1.4$ & $6.3 \pm 1.3^{*}$ \\
\hline Potassium & $(\mathrm{mg})$ & $3161 \pm 1105$ & $3327 \pm 1189$ & (mg/1000 kcal) & $1694 \pm 406$ & $1714 \pm 410+$ \\
\hline
\end{tabular}


Table 4 Associations between nutritional intake and MetS (Continued)

\begin{tabular}{lllllll}
\hline Calcium & $(\mathrm{mg})$ & $664 \pm 261$ & $688 \pm 276$ & $(\mathrm{mg} / 1000 \mathrm{kcal})$ & $355 \pm 105$ & $354 \pm 102$ \\
Magnesium & $(\mathrm{mg})$ & $300 \pm 99$ & $311 \pm 104$ & $(\mathrm{mg} / 1000 \mathrm{kcal})$ & $161 \pm 33$ & $160 \pm 32+$ \\
Vitamin D & $(\mu \mathrm{g})$ & $20.8 \pm 13.6$ & $21.0 \pm 14.0$ & $(\mathrm{\mu g} / 1000 \mathrm{kcal})$ & $10.9 \pm 5.7$ & $10.6 \pm 5.8$ \\
Vitamin B1 & $(\mathrm{mg})$ & $0.90 \pm 0.31$ & $0.93 \pm 0.31$ & $(\mathrm{mg} / 1000 \mathrm{kcal})$ & $0.48 \pm 0.09$ & $0.48 \pm 0.09$ \\
Vitamin B2 & $\underline{(\mathrm{mg})}$ & $\underline{1.52 \pm 0.50}$ & $\underline{1.56} \pm \underline{0.51}$ & $\underline{(\mathrm{mg} / 1000 \mathrm{kcal})}$ & $\underline{0.82} \pm \underline{0.19}$ & $\underline{0.80}$ \\
\hline \hline
\end{tabular}

Values are crude and energy-adjusted means \pm SD. MetS metabolic syndrome, w/o without

*Significant difference in crude or energy-adjusted nutrient intake (/1000 kcal) between in the subject with MetS and without MetS ( $p<0.05$ )

†Significant difference in energy-adjusted nutrient intake $(/ 1000 \mathrm{kcal})$ between in the subject with MetS and without MetS adjusted by age $(p<0.05)$

Table 5 Associations between Food Group Intake and MetS

\begin{tabular}{|c|c|c|c|c|c|c|}
\hline \multirow[t]{2}{*}{ Men } & & \multicolumn{3}{|l|}{ Crude } & \multicolumn{2}{|l|}{ Energy adjusted } \\
\hline & & MetS $(n=535)$ & $\begin{array}{l}\text { w/o MetS } \\
(n=2067)\end{array}$ & & MetS $(n=535)$ & $\begin{array}{l}\text { w/o MetS } \\
(n=2067)\end{array}$ \\
\hline Cereals & (g) & $533 \pm 200$ & $553 \pm 202^{*}$ & (g/1000 kcal) & $231 \pm 71$ & $234 \pm 63$ \\
\hline Potatoes & (g) & $76 \pm 69$ & $82 \pm 64$ & (g/1000 kcal) & $31 \pm 25$ & $33 \pm 24 t$ \\
\hline Bean and soybean product & (g) & $77 \pm 46$ & $83 \pm 50^{*}$ & (g/1000 kcal) & $33 \pm 19$ & $35 \pm 19+$ \\
\hline Green and yellow vegetables & (g) & $126 \pm 81$ & $136 \pm 87^{*}$ & (g/1000 kcal) & $54 \pm 35$ & $57 \pm 35 \dagger$ \\
\hline Light-colored vegetables & (g) & $217 \pm 119$ & $225 \pm 130$ & (g/1000 kcal) & $93 \pm 48$ & $94 \pm 48$ \\
\hline Fruits & (g) & $115 \pm 100$ & $118 \pm 100$ & (g/1000 kcal) & $50 \pm 43$ & $50 \pm 42$ \\
\hline Fish and shellfish & (g) & $126 \pm 80$ & $125 \pm 83$ & (g/1000 kcal) & $53 \pm 26$ & $51 \pm 26$ \\
\hline Meats & (g) & $68 \pm 40$ & $76 \pm 49 *$ & (g/1000 kcal) & $29 \pm 15$ & $31 \pm 16^{*}+$ \\
\hline Milk and dairy product & (g) & $143 \pm 107$ & $154 \pm 109^{*}$ & (g/1000 kcal) & $62 \pm 45$ & $66 \pm 48 \dagger$ \\
\hline Fat and oil & (g) & $19 \pm 12$ & $19 \pm 12$ & (g/1000 kcal) & $8 \pm 4$ & $8 \pm 5$ \\
\hline Confectionery & (g) & $39 \pm 40$ & $43 \pm 41^{*}$ & (g/1000 kcal) & $16 \pm 13$ & $17 \pm 14^{*} \dagger$ \\
\hline Preference for beverages & (g) & $1020 \pm 488$ & $950 \pm 421^{*}$ & (g/1000 kcal) & $443 \pm 192$ & $414 \pm 187^{*} \dagger$ \\
\hline \multirow[t]{3}{*}{ Women } & & \multicolumn{3}{|l|}{ Crude } & \multicolumn{2}{|l|}{ Energy adjusted } \\
\hline & & MetS & w/o MetS & & MetS & w/o MetS \\
\hline & & $(n=113)$ & $(n=1731)$ & & $(n=113)$ & $(n=1731)$ \\
\hline Cereals & (g) & $403 \pm 139$ & $393 \pm 129$ & (g/1000 kcal) & $217 \pm 61$ & $207 \pm 59+$ \\
\hline Potatoes & (g) & $69 \pm 50$ & $81 \pm 59^{*}$ & (g/1000 kcal) & $37 \pm 25$ & $41 \pm 27 \dagger$ \\
\hline Bean and soybean product & (g) & $73 \pm 41$ & $77 \pm 45$ & (g/1000 kcal) & $39 \pm 20$ & $40 \pm 22$ \\
\hline Green and yellow vegetables & (g) & $140 \pm 80$ & $149 \pm 88$ & (g/1000 kcal) & $75 \pm 41$ & $77 \pm 42$ \\
\hline Light-colored vegetables & (g) & $246 \pm 123$ & $252 \pm 129$ & (g/1000 kcal) & $130 \pm 52$ & $130 \pm 59$ \\
\hline Fruits & (g) & $132 \pm 89$ & $137 \pm 97$ & (g/1000 kcal) & $72 \pm 50$ & $71 \pm 48$ \\
\hline Fish and shellfish & (g) & $119 \pm 71$ & $116 \pm 73$ & (g/1000 kcal) & $63 \pm 31$ & $59 \pm 30$ \\
\hline Meats & (g) & $59 \pm 39$ & $65 \pm 38$ & (g/1000 kcal) & $31 \pm 17$ & $33 \pm 16$ \\
\hline Milk and dairy product & (g) & $147 \pm 90$ & $147 \pm 93$ & (g/1000 kcal) & $80 \pm 50$ & $77 \pm 47$ \\
\hline Fat and oil & (g) & $16 \pm 11$ & $17 \pm 12$ & (g/1000 kcal) & $8 \pm 5$ & $9 \pm 5$ \\
\hline Confectionery & (g) & $48 \pm 35$ & $54 \pm 42$ & (g/1000 kcal) & $25 \pm 18$ & $27 \pm 18$ \\
\hline Preference for beverages & (g) & $678 \pm 289$ & $717 \pm 319$ & (g/1000 kcal) & $377 \pm 174$ & $384 \pm 182$ \\
\hline
\end{tabular}

Values are crude and energy-adjusted means \pm SD. MetS metabolic syndrome. w/o without

*Significant difference in crude or energy-adjusted food group intake (/1000 kcal) between in the subject with MetS and without MetS ( $p<0.05$ )

†Significant difference in energy-adjusted food group intake (/1000 kcal) between in the subject with MetS and without MetS adjusted by age $(p<0.05)$ 


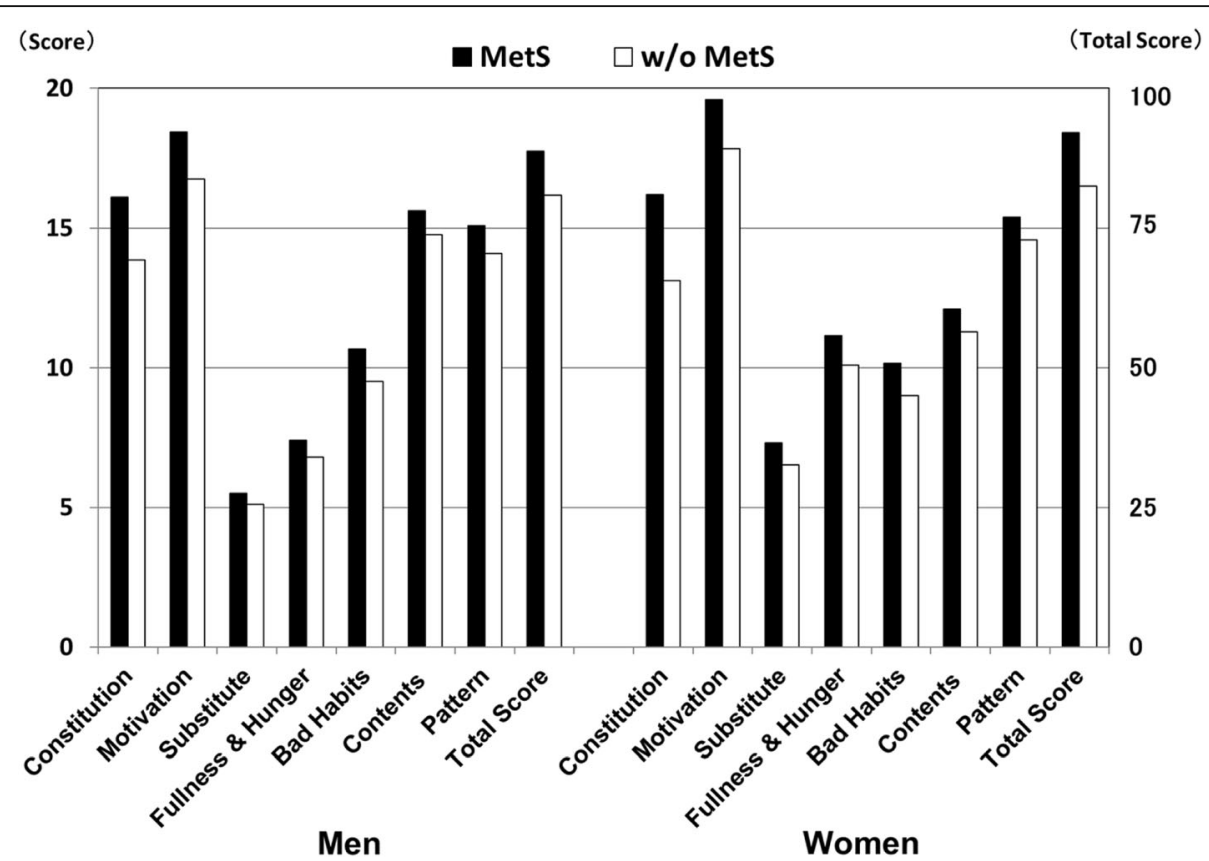

Fig. 2 Associations between eating behavior and MetS. Eating behaviors were assessed by a questionnaire included 55 items by the Japan Society for the Study of Obesity. Scores were calculated based on a 4-point Likert scale for the following eight eating behavior categories: 1 Constitution: perception gap about constitution and weight. 2 Motivation: motivation for eating. 3 Substitute: substitute eating (e.g., emotional eating). 4 Fullness and hunger: perception gap about feeling of fullness and hunger. 5 Bad habits: bad eating habits. 6 Contents: contents of diet. 7 Pattern: eating pattern. 8 Total score. The scores of all the categories in eating behavior were significantly worse in subjects with MetS than those without MetS $(p<0.05)$. MetS: metabolic syndrome, w/o: without

Thus, we were only able to suggest, and not determine, the causal direction in the association of eating behavior and dietary intake with MetS. The subjects with MetS may consciously decrease their dietary intakes through recognition of their obesity or hypertension previously. However, the eating behavior score in the subjects with MetS was obviously worse, so we did not expect their self-improvement of lifestyle, including diet. Second, physical activity is an important factor for weight loss and prevention of MetS as well as diet [30, 31], but we did not consider that factor in the present study. We assessed the participants' physical activity levels by triaxial accelerometry (Actimarker EW4800, Panasonic Electric Works, Newark, NJ) and some self-administered questionnaires. Unfortunately, we have not finished calculating all parameters for physical activity yet. Next, in analyzing the study, we can use the data of the physical activity. Although smoking and alcohol drinking have been reported to be related to MetS, especially in men [32], smoking and alcohol drinking data were not available, and the analysis could not be adjusted for smoking and alcohol drinking as potential confounding factors. In near future, smoking and alcohol drinking data of this cohort will be available. Finally, the present study's generality is limited because the participants of this study were healthy community residents seen for general health checkups every year. Assuming many people with metabolic syndrome were excluded because of their comorbidities, the prevalence of metabolic syndrome, particularly in women, was very low.

Many epidemiologic cohort studies have been implemented to develop adequate dietary behavior for MetS prevention. Nevertheless, there are inconsistencies and gaps in the evidence, and additional research is needed to define the most appropriate therapies for MetS.

We have been going on analyzing data of this cohort retrospectively and prospectively.

\section{Conclusions}

In this baseline study, dietary intake differences between subjects with Mets and without Mets were small. The scores of all the eating behavior categories were obviously worse in subjects with MetS than without MetS. It was suggested that the problem lay in the quality of diet, not in the quantity, caused by bad eating habits. The potential influence of eating behavior and nutritional intake on MetS was presented in men and women.

\section{Supplementary Information}

The online version contains supplementary material available at https://doi. org/10.1186/s40101-020-00250-w.

Additional file 1:. Sakata's eating behavior questionnaire. 


\section{Abbreviations}

MetS: Metabolic syndrome; BMI: Body mass index; SCOP: Saku Control Obesity Program; OGTT: Oral glucose tolerance test; VFA: Visceral fat area; CT: Computed tomography; HbA1c: Hemoglobin A1c; HDL: High-density lipoprotein; LDL: Low-density lipoprotein; JDS: Japan Diabetes Society; NGSP: National Glycohemoglobin Standardization Program; HOMAIR: Homeostasis model assessment of insulin resistance; BDHQ: Brief-type selfadministered diet history questionnaire; DHQ: Self-administered diet history questionnaire; ANCOVA: Analysis of covariance; NHNS: National Health and Nutrition Survey; DASH: Dietary Approaches to Stop Hypertension

\section{Acknowledgements}

The authors are indebted to the dedicated and committed participants of this study. We are grateful for the invaluable contribution of Kijo Deura (Saku Central Hospital, Saku, Japan). We are thankful to medical staff and colleagues for supporting this study in Saku Central Hospital for their kind cooperation. We thank Jun Yasukawa and Kaoru Morita (Koshien University, Takarrazuka, Japan) to assist this study.

\section{Authors' contributions}

AM wrote the manuscript and researched data. NA, MM, and SW contributed to the discussion and reviewed and edited the manuscript. All authors read and approved the final manuscript.

\section{Funding}

This study was supported by Japan Health Labor Sciences Research Grant (H21-Junkanki-Ippan- 013) to SW.

\section{Availability of data and materials}

Data sharing is not applicable to this article as no datasets were generated during the current study.

\section{Ethics approval and consent to participate}

The research plan was approved by the Ethical Committee of the National Institute of Health and Nutrition and Saku Central Hospital. Written informed consent was obtained from all participants before the study was initiated.

\section{Consent for publication}

Informed consent was obtained from all individual participants included in the study.

\section{Competing interests}

The authors declare that they have no competing interests.

\section{Author details}

'Department of Public Health and Occupational Medicine, Mie University Graduate School of Medicine, 2-174 Edobashi, Tsu, Mie 5148507, Japan. ${ }^{2}$ Department of Nutrition and Life Science, Kanagawa Institute of Technology, Kanagawa 243-0292, Japan. ${ }^{3}$ Department of Physical Activity Research, National Institutes of Biomedical Innovation, Health and Nutrition, Tokyo 162-8636, Japan. ${ }^{4}$ Life Science Promoting Association, Tokyo 160-0015, Japan.

\section{Received: 22 October 2020 Accepted: 26 November 2020}

\section{Published online: 14 December 2020}

\section{References}

1. Alberti KGMM, Zimmet P, Shaw J. The metabolic syndrome-a new worldwide definition. Lancet. 2005;366:1059-62. https://doi.org/10.1016/ s0140-6736(05)67402-8.

2. Numao S, Katayama Y, Nakata Y, Matsuo T, Nakagaichi M, Tanaka K. Association of abdominal fat with metabolic syndrome components in overweight women: effect of menopausal status. J Physiol Anthropol. 2020; 39:12-9. https://doi.org/10.1186/s40101-020-00222-0..

3. Nishi N. The 2nd health Japan 21: goals and challenges. J Fed Am Soc Exp Biol. 2014;28(1):632.19. https://doi.org/10.1096/fasebj.28.1_supplement.632.19.

4. Pérez-Martínez P, Mikhailidis DP, Athyros VG, Bullo M, Couture P, Covas MI, de Koning L, Delgado-Lista J, Díaz-López A, Drevon CA, Estruch R, Esposito K, Fitó M, Garaulet M, Giugliano D, García-Ríos A, Katsiki N, Kolovou G, Lamarche B, Maiorino MI, Mena-Sánchez G, Muñoz-Garach A, Nikolic D, Ordovás JM, Pérez-Jiménez F, Rizzo M, Salas-Salvadó J, Schröder H,
Tinahones FJ, de la Torre R, van Ommen B, Wopereis S, Ros E, LópezMiranda J. Lifestyle recommendations for the prevention and management of metabolic syndrome: an international panel recommendation. Nutr. Rev. 2017;75:307-26. https://doi.org/10.1093/nutrit/nux014.

5. Castro-Barquero S, Ruiz-León AM, Sierra-Pérez M, Estruch R, Casas R. Dietary strategies for metabolic syndrome: a comprehensive review. Nutrients. 2020 Sep 29;12(10):E2983. https://doi.org/10.3390/nu12102983.

6. Gabriel AS, Ninomiya K, Uneyama $\mathrm{H}$. The role of the Japanese traditional diet in healthy and sustainable dietary patterns around the world. Nutrients. 2018;10:173. https://doi.org/10.3390/nu10020173.

7. Asano M, Kushida M, Yamamoto K, Tomata Y, Tsuji I, Tsuduki T. Abdominal Fat in Individuals with Overweight Reduced by Consumption of a 1975 Japanese Diet: A Randomized Controlled Trial. Obesity (Silver Spring). 2019 Jun;27(6):899-907. https://doi.org/10.1002/oby.22448.

8. Oba S, Nagata C, Nakamura K, Fujii K, Kawachi T, Takatsuka N, Shimizu H. Diet based on the Japanese Food Guide Spinning Top and subsequent mortality among men and women in a general Japanese population. J Am Diet Assoc. 2009 Sep;109(9):1540-7. https://doi.org/10.1016/j.jada.2009.06.367.

9. Kurotani K, Akter S, Kashino I, Goto A, Mizoue T, Noda M, Sasazuki S, Sawada N, Tsugane S. Japan Public Health Center based Prospective Study Group. Quality of diet and mortality among Japanese men and women: Japan Public Health Center based prospective study. BMJ. 2016;352:11209. https:// doi.org/10.1136/bmj.i1209.

10. Murakami K, Shinozaki N, Fujiwara A, Yuan X, Hashimoto A, Fujihashi H, Wang HC, Livingstone MBE, Sasaki S. A systematic review of principal component analysis-derived dietary patterns in Japanese adults: Are major dietary patterns reproducible within a country? Adv Nutr. 2019;10:237-49. https://doi.org/10.1093/advances/nmy079.

11. Watanabe S, Tsugane S, Sobue T, Konishi M, Baba S. Study design and organization of the JPHC study. Japan public health center-based prospective study on cancer and cardiovascular diseases. J Epidemiol. 2001; 11 (6 Suppl):S3-7.

12. Watanabe S, Morita A, Aiba N, Miyachi M, Sasaki S, Morioka M. Study design of the SAKU control obesity program (SCOP). Anti-aging Med. 2007;4(2):703. https://doi.org/10.3793/jaam.4.70.

13. Morita A, Ohmori Y, Suzuki N, Ide N, Morioka M, Aiba N, Sasaki S, Miyachi M, Noda M, Watanabe S. Anthropometric and clinical findings in obese Japanese: The Saku Control Obesity Program (SCOP). Anti-aging Med. 2008; 5(1):13-6. https://doi.org/10.3793/jaam.5.13.

14. Nakade M, Aiba N, Suda N, Morita A, Miyachi M, Sasaki S, Watanabe S, SCOP Group. Behavioral change during weight loss program and one-year followup: Saku Control Obesity Program (SCOP) in Japan. Asia Pac J Clin Nutr. 2012;21 (1):22-34 http://apjen.nhri.org.tw/server/APJCN/21/1/22.pdf.

15. Tanaka NI, Murakami H, Aiba N, Morita A, Watanabe S, Miyachi M. Saku Control Obesity Program (SCOP) Study Group. Effects of 1-year weight loss intervention on abdominal skeletal muscle mass in Japanese overweight men and women. Asia Pac J Clin Nutr. 2019;28(1):72-8. https://doi.org/10. 6133/apjcn.201903_28(1).0011.

16. Goto A, Morita A, Goto M, Sasaki S, Miyachi M, Aiba N, Kato M, Terauchi Y, Noda M. Watanabe S; Saku Cohort Study Group. Validity of diabetes selfreports in the Saku diabetes study. J Epidemiol. 2013;23:295-300. https://doi. org/10.2188/jea.JE20120221.

17. Kobayashi S, Murakami K, Sasaki S, Okubo H, Hirota N, Notsu A, Fukui M, Date C. Comparison of relative validity of food group intakes estimated by comprehensive and brief-type self-administered diet history questionnaires against 16 d dietary records in Japanese adults. Public Health Nutr. 2011;14: 1200-11. https://doi.org/10.1017/s1368980011000504.

18. Kobayashi S, Honda S, Murakami K, Sasaki S, Okubo H, Hirota N, Notsu A, Fukui M, Date C. Both comprehensive and brief self-administered diet history questionnaires satisfactorily rank nutrient intakes in Japanese adults. J. Epidemiol. 2012;22:151-9. https://doi.org/10.2188/jea.je20110075.

19. Japan Obesity Association Edit Committee Guidance. Manual of obesity. Ishiyaku Co. Ltd., Tokyo; 2001. p. 114-8.

20. Committee to Evaluate Diagnostic Standards for Metabolic Syndrome. Definition and the diagnostic standard for metabolic syndrome Committee to Evaluate Diagnostic Standards for Metabolic Syndrome. Nihon Naika Gakkai Zasshi. 2005;94:794-809. https://doi.org/10.2169/naika.94.794 In Japanese.

21. Ministry of Health, Labour and Welfare, Japan. The National Health and Nutrition Survey, Japan. Available online: http://www.mhlw.go.jp/bunya/ 
kenkou/kenkou_eiyou_chousa.html (accessed on 18 Oct 2020). (In Japanese).

22. Htun NC, Suga H, Imai S, Shimizu W, Takimoto H. Food intake patterns and cardiovascular risk factors in Japanese adults: analyses from the 2012 National Health and nutrition survey. Japan. Nutr J. 2017;16(1):61. https://doi. org/10.1186/s12937-017-0284-z..

23. Tobias DK, Chen M, Manson JE, Ludwig DS, Willett W, Hu FB. Effect of lowfat diet interventions versus other diet interventions on long-term weight change in adults: a systematic review and meta-analysis. Lancet Diabetes Endocrinol. 2015;3:968-79. https://doi.org/10.1016/S2213-8587(15)00367-8.

24. Kastorini CM, Milionis HJ, Esposito K, Giugliano D, Goudevenos JA, Panagiotakos DB. The effect of Mediterranean diet on metabolic syndrome and its components: a meta-analysis of 50 studies and 534,906 individuals. J Am Coll Cardiol. 2011;57:1299-313. https://doi.org/10.1016/j.jacc.2010.09.073.

25. Azadbakht L, Mirmiran P, Esmaillzadeh A, Azizi T, Azizi F. Beneficial effects of a Dietary Approaches to Stop Hypertension eating plan on features of the metabolic syndrome. Diabetes Care. 2005;28:2823-31. https://doi.org/10. 2337/diacare.28.12.2823.

26. Uusitupa M, Hermansen K, Savolainen MJ, Schwab U, Kolehmainen M, Brader L, Mortensen LS, Cloetens L, Johansson-Persson A, Onning G, LandinOlsson M, Herzig KH, Hukkanen J, Rosqvist F, Iggman D, Paananen J, Pulkki K, Siloaho M, Dragsted L, Barri T, Overvad K, Bach Knudsen KE, Hedemann MS, Arner P, Dahlman I, Borge GI, Baardseth P, Ulven SM, Gunnarsdottir I, Jónsdóttir S, Thorsdottir I, Orešič M, Poutanen KS, Risérus U, Akesson B. Effects of an isocaloric healthy Nordic diet on insulin sensitivity, lipid profile and inflammation markers in metabolic syndrome-a randomized study (SYSDIET). J Intern Med. 2013;274:52-66. https://doi.org/10.1111/joim.12044.

27. Rizzo NS, Sabate J, Jaceldo-Siegl K, Gary EF. Vegetarian dietary patterns are associated with a lower risk of metabolic syndrome: the Adventist Health Study 2. Diabetes Care. 2011;34:1225-7. https://doi.org/10.2337/dc10-1221.

28. Ikeda N, Saito E, Kondo N, Inoue M, Ikeda S, Satoh T, Wada K, Stickley A, Katanoda K, Mizoue T, Noda M, Iso H, Fujino Y, Sobue T, Tsugane S, Naghavi M, Ezzati M, Shibuya K. What has made the population of Japan healthy? Lancet. 2011;378:1094-105. https://doi.org/10.1016/S0140-6736(11)61055-6.

29. Tsugane $\mathrm{S}$. Why has Japan become the world's most long-lived country: insights from a food and nutrition perspective. Eur J Clin Nutr. 2020. https://doi.org/10.1038/s41430-020-0677-5.

30. Schwingshackl L, Dias S, Hoffmann G. Impact of long-term lifestyle programmes on weight loss and cardiovascular risk factors in overweight/ obese participants: a systematic review and network meta-analysis. Syst Rev. 2014;3:130. https://doi.org/10.1186/2046-4053-3-130.

31. Kim B, Ku M, Kiyoji T, Isobe T, Sakae T, Oh S. Cardiorespiratory fitness is strongly linked to metabolic syndrome among physical fitness components: a retrospective cross-sectional study. J Physiol Anthropol. 2020;39:30. https://doi.org/10.1186/s40101-020-00241-X.

32. Nakashita Y, Nakamura M, Kitamura A, Kiyama M, Ishikawa Y, Mikami H. Relationships of cigarette smoking and alcohol consumption to metabolic syndrome in Japanese men. J Epidemiol. 2010;20(5):391-7. https://doi.org/ 10.2188/jea.je20100043.

\section{Publisher's Note}

Springer Nature remains neutral with regard to jurisdictional claims in published maps and institutional affiliations.

\section{Ready to submit your research? Choose BMC and benefit from}

- fast, convenient online submission

- thorough peer review by experienced researchers in your field

- rapid publication on acceptance

- support for research data, including large and complex data types

- gold Open Access which fosters wider collaboration and increased citations

- maximum visibility for your research: over $100 \mathrm{M}$ website views per year

At BMC, research is always in progress.

Learn more biomedcentral.com/submissions 